\title{
Cauliflower Leave, an Agricultural Waste Biomass Adsorbent, and Its Application for the Removal of MB Dye from Aqueous Solution: Equilibrium, Kinetics, and Thermodynamic Studies
}

\author{
Seraj Anwar Ansari, Fauzia Khan, and Anees Ahmad \\ Industrial Chemistry Research Laboratory, Department of Chemistry, Aligarh Muslim University, Aligarh 202002, India \\ Correspondence should be addressed to Anees Ahmad; prof.anees.ahmad@gmail.com
}

Received 18 June 2016; Revised 29 August 2016; Accepted 30 August 2016

Academic Editor: Francesca Pagnanelli

Copyright (C) 2016 Seraj Anwar Ansari et al. This is an open access article distributed under the Creative Commons Attribution License, which permits unrestricted use, distribution, and reproduction in any medium, provided the original work is properly cited.

\begin{abstract}
Cauliflower leaf powder (CLP), a biosorbent prepared from seasonal agricultural crop waste material, has been employed as a prospective adsorbent for the removal of a basic dye, methylene blue (MB) from aqueous solution by the batch adsorption method under varying conditions, namely, initial dye concentration, adsorbent dose, solution $\mathrm{pH}$, and temperature. Characterization of the material by FTIR and SEM indicates the presence of functional groups and rough coarse surface suitable for the adsorption of methylene blue over it. Efforts were made to fit the isotherm data using Langmuir, Freundlich, and Temkin equation. The experimental data were best described by Freundlich isotherm model, with an adsorption capacity of $149.22 \mathrm{mg} / \mathrm{g}$ at room temperature. To evaluate the rate of methylene blue adsorption onto CLP, pseudo-first-order, pseudo-second-order, and intraparticle diffusion models were employed. The experimental data were best described by the pseudo-second-order kinetic model. Evaluation of thermodynamic parameters such as changes in enthalpy, entropy, and Gibbs' free energy showed the feasible, spontaneous, and exothermic nature of the adsorption process. On the basis of experimental results obtained, it may be concluded that the CLP prepared from agricultural waste has considerable potential as low-cost adsorbent in wastewater treatment for the removal of basic dye, MB.
\end{abstract}

\section{Introduction}

The increasing demand for commercial dyes by various industries leads to the vast production of dyes. Over 100000 commercial dyes are available and more than $7 \times 10^{5}$ tons are produced annually, of which a significant portion is being discharged directly into the aqueous media $[1,2]$. In developing nations, environmental pollution, particularly water pollution, which arises due to the discharge of unprocessed industrial effluents into main water streams is of major concern. These effluents containing dyes and pigments are regularly discharged into the natural water bodies by industries like food, textile, cosmetics, rubber, plastics, paper, pharmaceuti$\mathrm{cal}$, and so forth. These dyes have so many adverse effects not only on the aquatic flora and fauna but also on the human health. Large water bodies can be colored even with small quantities of dyes, which not only affect visual quality but also diminish light penetration and photosynthesis. Many of these dyes are of toxic nature and have cancer-causing and mutagenic effects. So the effluents containing these coloring agents have to be removed appropriately earlier that they are discharged into the aquatic forms [3, 4]. Among these dyes, methylene blue $(\mathrm{MB})$ is frequently used coloring substance for dying cotton, wood, and silk. Although methylene blue is not so harmful, it can cause harmful effect upon inhalation. Severe contact to methylene blue can cause increased heart rate, vomiting, tremor, Heinz body formation due to damage of hemoglobin component, cyanosis or blue disease, jaundice, quadriplegia, and tissue necrosis in humans [5], while ingestion through the mouth creates a hot feeling causing nausea, diarrhea, and gastric problems. Accidental large dose creates pain in abdomen and chest and head, abundant sweating, mental confusion, painful micturition, and methemoglobinemia [6]. This shows the necessity for effective removal of 
the dye from the effluent. During the previous year, several technologies comprising biological, chemical, and physical methods have been reported for the effective removal of dyes from polluted water $[7,8]$. Among these approaches of dye removal, adsorption technique is one of the utmost operative methods for treatment of waste water in terms of cost, simple design, and easiness to operate. Adsorption is regarded as an easy, efficient, and economic process because it gives the best results with no harmful side products and therefore generates high quality treated effluents. Therefore, in recent years, this has prompted a growing research interest in using various conventional waste biomass by many researchers such as commercial activated carbons prepared by different activators, bioadsorbents, and wastes from agriculture such as coir pith, fruits peels, rice hull, saw dust, sugarcane bagasse, and wheat straw which have been used traditionally as an adsorbent for the removal of contagious pollutant $[2,9,10]$. In recent times, several approaches for the growth of economical and potent adsorbents have been studied. Various formal low-cost adsorbents including biosorbents, natural things, and waste materials from agriculture and industry have been suggested by a number of researchers for the removal of dyes from water. Some low-cost agricultural wastes like garlic peel [11], potato plant wastes [12], wild carrot (Daucus carota) [13], agricultural wastes-based activated carbons [14], cotton dust [15], chemically modified tea wastes [16], hazelnut husk activated carbon [17], rice husk and rice ash [18], tea wastes [19], fruit wastes (yellow passion) [20], plant stems (Haloxylon recurvum) [21], LDH bacteria aggregates [22], pine apple leaf powder [23], biomass (Arthrospira platensis) [24], and so forth have been efficiently used for the removal process but they suffer certain drawbacks as well.

Cauliflower, among the winter vegetables of the world, occupies an important place in the list. The crop is being grown across 3.8 million hectares in almost 150 diverse nations and produced around 70 million tons of cabbages annually. The major producer of this crop includes China, India, Spain, Italy, and France. The leaf of this vegetable is a waste product which can be gainfully utilized as a potential adsorbent for the elimination of methylene blue dye from waste water.

The main objective of the present study is to evaluate the potential of cauliflower leaf powder as an alternative adsorbent for the removal of methylene blue from aqueous media focusing on the adsorption capacity, optimization of various physicochemical parameters, and adsorption kinetics parameters. The equilibrium isotherms were described by various adsorption models and the isotherm constants were determined. In addition, the thermodynamic factors, such as change in enthalpy, entropy, and the free energy were also investigated in order to have a clear understanding of the reaction mechanisms and add a scientific basis to traditional uses of this vegetable.

\section{Materials and Methods}

2.1. Adsorbent: Cauliflower Leaf Powder (CLP). Cauliflower leaf was brought from nearby agricultural field and thoroughly washed with tap water to remove dirt and adhering impurities from it. Then leaves were sun-dried to evaporate the moisture content. After that, it was further oven-dried for $24 \mathrm{~h}$ at $80^{\circ} \mathrm{C}$ to remove additional moisture content from it. Finally it was grinded into fine powder with the help of domestic mixer grinder and screened with molecular sieve of 100 mesh size $(0.149 \mathrm{~mm})$. Then, the organic impurities from this powder of 100 mesh particle size were removed by washing with double distilled water under vacuum pressure. The washed material was then dried overnight in an oven at $105^{\circ} \mathrm{C}$. Finally dried material was grinded mechanically into fine powder with pastel and mortar and kept in desiccators for further use. No other physical or chemical treatments were performed prior to batch adsorption experiments.

2.2. Adsorbate: Methylene Blue. The basic dye methylene blue (MB), also known as Basic Blue 9, was obtained from SigmaAldrich and used as such without additional refining. The physical characteristics of the dye are listed in Table 1.

2.3. Adsorption Studies. Appropriate amount of MB dye (1 g) was dissolved in double distilled water to prepare a stock solution of methylene blue dye $\left(1000 \mathrm{mg} \mathrm{L}^{-1}\right)$; further desired concentration of adsorbate was prepared from the stock solution by diluting it. By varying one parameter under consideration and keeping other parameters constant, adsorbent dose, contact time, the effect of $\mathrm{pH}$, initial dye concentration, and temperature on the adsorption of methylene blue dye on CLP were investigated. In each experiment, a preweighed amount of CLP was added to $20 \mathrm{~mL}$ of dye solution in a $100 \mathrm{~mL}$ conical flask and agitated at $90 \mathrm{rpm}$ using a stirrer at room temperature for a given period of time. The dye concentration in supernatant solution was determined at wavelength of maximum absorption $\left(\lambda_{\max }\right)$, that is, $664 \mathrm{~nm}$, by double beam UV-visible spectrophotometer (PerkinElmer $\lambda-25$ ).

The amount of dye adsorbed $\left(q_{e}^{\text {exp }}\right)$ and percentage dye adsorbed $(\% R)$ on CLP were calculated by (1) and (2), receptively [25]:

$$
\begin{aligned}
& q_{e}^{\exp }=\frac{\left(C_{i}-C_{e}\right) \cdot V}{w}, \\
& \% R=\frac{100 \cdot\left(C_{i}-C_{e}\right)}{C_{i}},
\end{aligned}
$$

where $q_{e}^{\text {exp }}$ is quantity adsorbed on the adsorbent at equilibrium $\left(\mathrm{mg} \mathrm{g}^{-1}\right), C_{i}$ and $C_{e}$ are the initial and equilibrium concentration $\left(\mathrm{mg} \mathrm{L}^{-1}\right)$ of dye in solution, respectively, $V$ is the solution volume taken $(\mathrm{L})$, and $w$ is the mass of the adsorbent (g). All experiments were done three times and the mean values were used in data analysis.

2.4. Regeneration of the Adsorbent. For the frequent applications of used adsorbent (CLP), it was regenerated. The preweighed amount of used CLP was kept in $20 \mathrm{~mL}$ of $0.01 \mathrm{M}$ different solvents such as $\mathrm{H}_{2} \mathrm{SO}_{4}, \mathrm{HNO}_{3}, \mathrm{CH}_{3} \mathrm{COOH}$, and $\mathrm{NaOH}$ and was agitated for predetermined time interval and filtrate was measured spectrophotometrically. It was found that the adsorbent can be successfully regenerated with acidic 
TABLE 1: Physical and chemical properties of adsorbate (methylene blue).

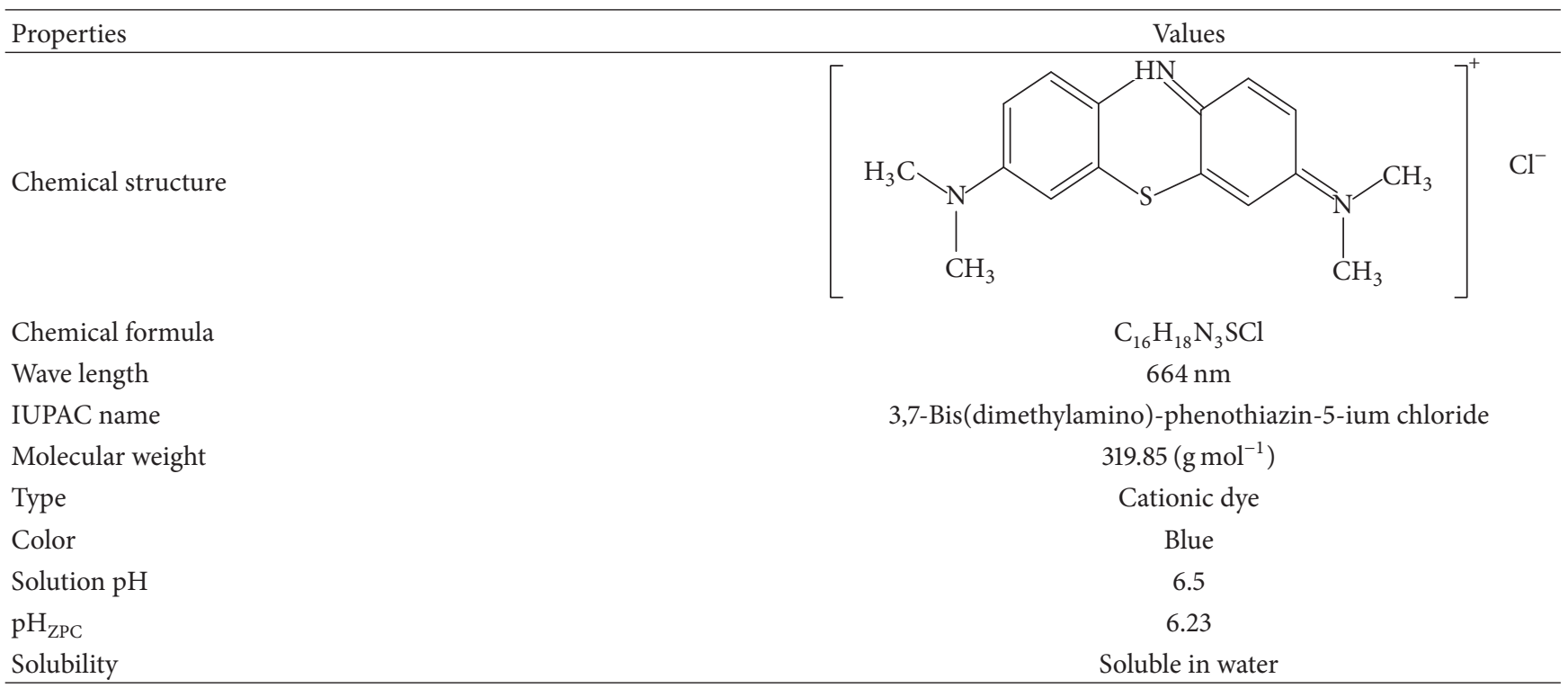

solvents up to 6 successful cycles. After each cycle, adsorption capacity of the regenerated adsorbent gets reduced. The reduction in adsorption capacity was found from $164.23 \mathrm{mg} \mathrm{g}^{-1}$ to $111.25 \mathrm{mg} \mathrm{g}^{-1}$. Since adsorbent CLP used in this study for the $\mathrm{MB}$ dye removal is fairly inexpensive and freely obtainable, therefore regeneration does not seem to be certainly obligatory.

2.5. Error Analysis. In order to find most appropriate isotherm model for demonstrating the experimental data, chi square $\left(\chi^{2}\right)$, sum of squared error (SSE), sum of absolute error (SAE), and Marquardt's percent standard deviation (MPSD) error functions were applied and the model showing minimum error was calculated by the using following equation and is tabulated in Table 3.

Chi square, $\chi^{2}$ is as follows:

$$
\chi^{2}=\sum_{i=1}^{n}\left[\frac{q_{e}^{\mathrm{exp}}-q_{e}^{\mathrm{cal}}}{q_{e}^{\mathrm{cal}}}\right] .
$$

\section{Results and Discussion}

3.1. Characterization of CLP. The FTIR study was carried out using potassium bromide disc method over the wavelength region $4,000 \mathrm{~cm}^{-1}-400 \mathrm{~cm}^{-1}$ to determine the presence of functional groups before and after the adsorption. The FTIR spectra were recorded on a FTIR spectrophotometer (PerkinElmer, version 10.4.00). Figure 1(a) shows the FTIR spectrum of CLP before the adsorption of MB. The appearance of a broad peak at $3352 \mathrm{~cm}^{-1}$ is due to the stretching vibration of free- $\mathrm{OH}$ or - $\mathrm{NH}$ (str.) on the adsorbent surface as in pectin [26]. The peaks at $2921 \mathrm{~cm}^{-1}$ and $2851 \mathrm{~cm}^{-1}$ indicate the $\mathrm{C}-\mathrm{H}$ stretching mode of aliphatic compounds. Peaks detected at $1738 \mathrm{~cm}^{-1}, 1628 \mathrm{~cm}^{-1}, 1418 \mathrm{~cm}^{-1}, 1322 \mathrm{~cm}^{-1}$, and $1244 \mathrm{~cm}^{-1}$ correspond to $\mathrm{C}=\mathrm{O}$ stretching, aromatic $\mathrm{C}=\mathrm{C}$ bending, C-C stretching (in ring) aromatic, N-O symmetric stretch of nitro compounds, and $\mathrm{C}-\mathrm{N}$ stretching of aliphatic amines, respectively. The peak at $1031 \mathrm{~cm}^{-1}$ might be due to $\mathrm{C}$ $\mathrm{O}$ stretching of alcohols, carboxylic acids, esters, and ethers present on the surface of the biomass. The peaks around $1100-1000 \mathrm{~cm}^{-1}$ are known to be characteristics for all sugar derivatives [21]. Figure 1(b) shows the spectra of CLP after the adsorption of methylene blue dye. Considerable changes in the frequencies of functional groups were observed after the adsorption of MB dye at the surface of CLP due to their involvement in sorption process either through formation of chemical complex or through physical van der Waals forces [27]. The surface morphology of adsorbent was studied by Scanning Electron Microscopy (SEM). Figure 2 shows the SEM micrograph of CLP at 2000x magnification before and after the adsorption of MB dye on its surface. Figure 2(a) revealed that the surface of CLP was found to be coarse and asymmetrical and has significant numbers of pores which provides requisite sites for sorption of $\mathrm{MB}$ dye molecule. Figure 2(b) showed that the MB molecules adsorbed at the surface of the adsorbent and therefore the morphology of the adsorbent surface has been changed significantly. A proposed mechanism of $\mathrm{MB}$ adsorption is shown in Figure 3.

3.2. Effect of $p H$. The $\mathrm{pH}$ of the solution controls the surface charge of the adsorbent and the degree of ionization of the pollutants. Since the effect of $\mathrm{pH}$ on the methylene blue adsorption on CLP was studied by varying the $\mathrm{pH}$ of dye solution over the range $1-10$, the desired $\mathrm{pH}$ of the solution was adjusted by using $0.1 \mathrm{M} \mathrm{HNO}_{3}$ and $0.1 \mathrm{M} \mathrm{NaOH}$ solutions. To see the effect of $\mathrm{pH}$, a series of experiments was done in a beaker containing $20 \mathrm{~mL}$ of dye solution and the desired $\mathrm{pH}$ was adjusted and $0.02 \mathrm{~g}$ CLP was added to the solution. The absorbance of the filtrate solution was taken at predetermined time. The biopolymers of biosorbent comprise many functional groups, so the net charge on the biosorbent is also 


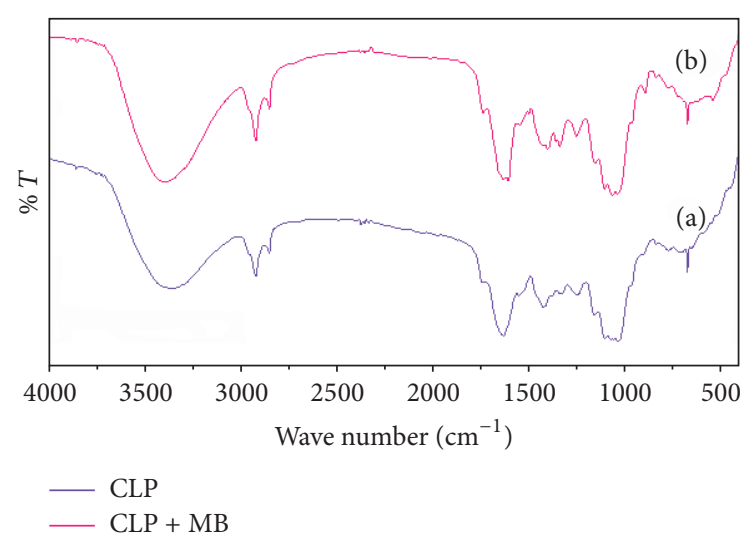

FIGURE 1: FT-IR spectra of CLP (a) before and (b) after the adsorption of methylene blue.

$\mathrm{pH}$ dependent [28]. The number of negatively charged sites on the biosorbent increase as the $\mathrm{pH}$ of the system increases whereas the number of positively charged sites decreases, due to increase in the hydroxyl ion concentration [29]. Figure 4(a) showed the MB dye adsorption onto the biosorbent. The nature of the curve is in agreement with the fact that $\mathrm{pH}$ of the adsorption system plays an important role in the biosorptive removal of the $\mathrm{MB}$ dye. At lower $\mathrm{pH}$, less number of negatively charge adsorbent cites and excess $\mathrm{H}^{+}$cites are available at the CLP surface. Therefore, the lower sorption of MB at lower $\mathrm{pH}$ was probably due to the presence of the excess $\mathrm{H}^{+}$ions competing with the cationic groups on the dye for sorption sites [30]. The maximum sorption of the MB (cationic or positively charged dye) dye was observed at $\mathrm{pH} 9$ because, at higher $\mathrm{pH}$, the surface of the CLP gets more negatively charged by losing protons (deprotonation of different functional groups on the surface of the biosorbent) and consequently supports the uptake of positively charged (cationic) dyes due to increased electrostatic force of attraction [31]. After that the decrease in the biosorption capacity of the CLP for MB decreases.

3.3. Effect of Concentration. To see the effect of concentration on the adsorption of methylene blue on CLP, different dye concentration over the range $10-200 \mathrm{mg}$ per liter was tested with initial adsorbent dose $0.02 \mathrm{~g}$. At predetermined time, the solution was centrifuged at $2000 \mathrm{rpm}$ for $10 \mathrm{~min}$ and filtrate was taken out with the help of syringe. The absorbance of the solution was measured spectrophotometrically. It can be seen from Figure 4(b) that as the concentration of adsorbate solution increases, the corresponding adsorption capacity also increases and reaches maximum at a point where the adsorption remains constant. There is no further improvement in adsorptive removal after that concentration. It may be concluded that the adsorption of MB at the surface of CLP is highly dependent on the initial concentration of the MB dye in solution and it increases, reaching up to a maximum value, while $\%$ removal of $\mathrm{MB}$ decreases as its initial concentration increases.
3.4. Effect of Adsorbent Dose. The amount of adsorbent plays an important role in the adsorption of $\mathrm{MB}$ dye from the aqueous solution. The plot between quantities of dye adsorbed $q_{e}$ against dose of adsorbent is shown in Figure 4(c). It is very clear from the plot that quantity of dye adsorbed is varied with varying adsorbent weight and it decreased with increasing adsorbent weight. The quantity of $\mathrm{MB}$ dye adsorbed drops from $149.2 \mathrm{mg}$ per gram to $17.74 \mathrm{mg}$ per gram when the adsorbent dose increases from $0.01 \mathrm{~g}$ to $0.1 \mathrm{~g}$ (not plotted), whereas \% removal increased from 74.81 to 88.1 for the same increment of adsorbent dose. At higher CLP to MB concentration ratio, there is a very fast superficial sorption onto the adsorbent surface that produces a lower solute (MB) concentration in the solution. When the CLP to MB concentration ration is lower, the superficial sorption onto the adsorbent surface is slow so higher concentration of solute $(\mathrm{MB})$ remains in the solution. The reason for this may be due to fact that a fixed amount of CLP adsorbent can only adsorb a certain amount of MB dye. The decrease in quantity adsorbed at the surface of the CLP adsorbent $\left(q_{e}\right)$ with increase in adsorbent dose is due to the concentration gradient or split in the flux between $\mathrm{MB}$ dye concentration in the solution and the MB concentration in the surface of CLP. Therefore, the amount of dye adsorbed onto unit mass of adsorbent decreased with increasing adsorbent weight, thus causing a fall in amount of dye adsorbed $\left(q_{e}\right)$ value with increasing the mass of adsorbent [32].

3.5. Effect of Ionic Strength. The adsorption capacity of an adsorbent is generally affected by high ionic strength present in waste water, attributed by the existence of salt in higher concentration. In order to see the effect of the salt on the adsorption behavior of an adsorbent, different concentration of $\mathrm{NaCl}$ over the range $0.0-0.1 \mathrm{M}$ was studied. Figure 5 shows contrary effect of ionic strength on the adsorption of $\mathrm{MB}$ dye at the surface of CLP. As the concentration of salt increases, the quantity of MB dye adsorbed at the surface of the CLP decreases and reaches constant value after which no reduction in the adsorption capacity of the CLP was observed. This behavior of decreasing adsorbed amount of dye at the surface of CLP with increasing the $\mathrm{NaCl}$ concentration is due to the fact that salt screens the electrostatic interaction between the opposite charges of the adsorbent surface and the dye molecule [33].

3.6. Adsorption Kinetic Studies. In order to efficaciously use agricultural by product as a potential adsorbent, contact time is of fundamental importance [34]. The equilibrium time specifies the promising diffusion control mechanism of the sorbet as it moves toward the sorption surface [35]. The effects of contact time on adsorption of methylene blue onto CLP were studied under predetermined experimental condition for $100 \mathrm{mg} \mathrm{L}^{-1}$ at 303,313 , and $323 \mathrm{~K}$. It can be seen from Figures $4(\mathrm{~d})$ and 6 that the rate of adsorption was very rapid at initial period of contact time and as the contact time increases, the adsorption capacities also increase. It reaches a maximum value after which there is no increment in adsorption capacity of the adsorbent. The rapid rise in the slope of the curve pointed to the rapid binding of the MB dye with 

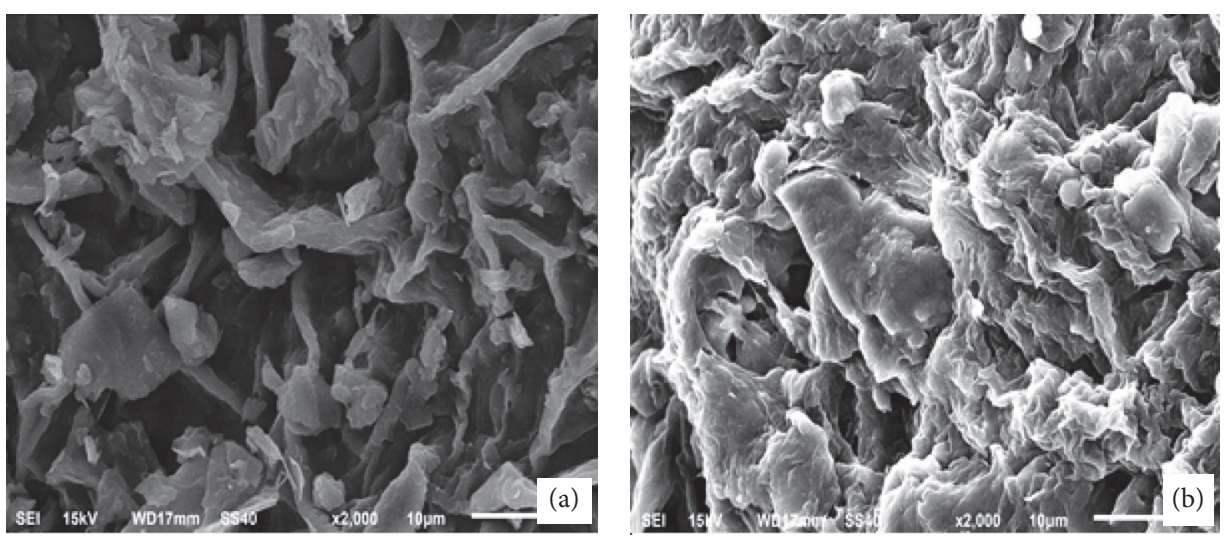

FIGURE 2: SEM image of CLP (a) before and (b) after the methylene blue adsorption.

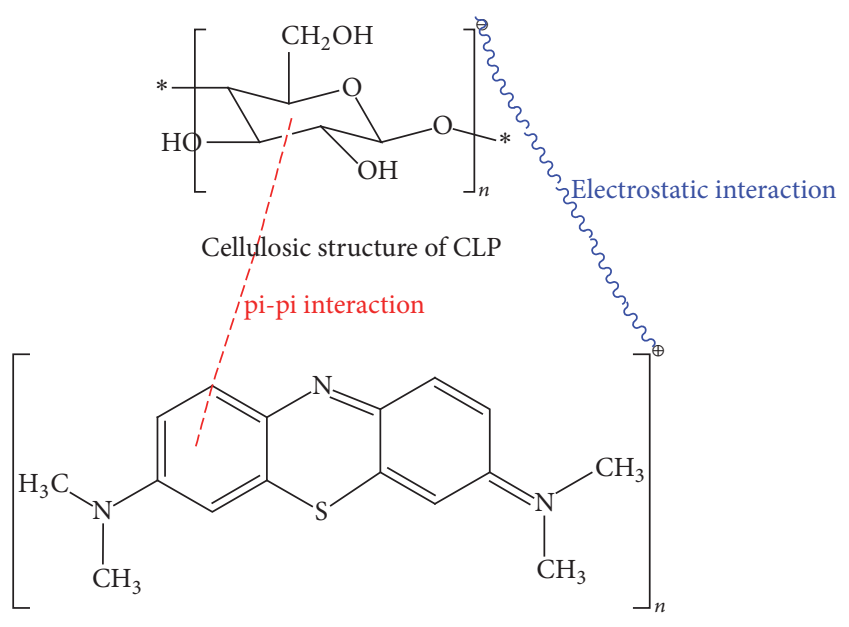

Methylene blue

FIGURE 3: Proposed mechanisms for the adsorption of methylene blue dye over CLP.

the CLP surface, that is, rapid adsorption region. This may be attributed due to greater number of vacant sites available on CLP adsorbent and strong attractive forces between the dye molecule and the adsorbent $[21,36]$. This rapid increase in adsorption capacities during initial stage showed that the nature of binding was a physical one [37]. As the contact time increases further, the number of vacant sites also decreases resulting in the decreased rate of dye binding [38]. The equilibrium time for adsorption of $\mathrm{MB}$ dye at the surface of CLP was found to be $100 \mathrm{~min}$ and thereafter there is no considerable change in the adsorption capacities of CLP adsorbent.

The adsorption kinetics of the methylene blue solution at the surface of CLP was studied for the concentration of 40 , 60,80 , and $100 \mathrm{mg} \mathrm{L}^{-1}$ and data were applied to Lagergren pseudo-first-order (3), Ho's pseudo-second-order (4) and intraparticle diffusion model (5) [39, 40]. Lagergren pseudofirst-order kinetics model, which is particularly suitable for low concentrations, indicates that the process of sorption occurs at a rate proportional to the dye concentration [39]. The second-order kinetics in which the rate controlling step is an exchange reaction is thought to derive from sorption processes [39].

$$
\begin{aligned}
\ln \left(q_{e}-q_{t}\right) & =\ln q_{e}-K_{1} t, \\
\frac{t}{q_{t}} & =\frac{1}{K_{2} q_{e}^{2}}+\frac{t}{q_{e}}, \\
q_{t} & =K_{i} t^{1 / 2}+C .
\end{aligned}
$$

In the above-mentioned equations, $q_{e}\left(\mathrm{mg} \mathrm{L}^{-1}\right)$ and $q_{t}$ $\left(\mathrm{mg} \mathrm{L}^{-1}\right)$ are the amounts of $\mathrm{MB}$ dye adsorbed at equilibrium and at any contact time of adsorption $t$ (min.), respectively; $K_{1}\left(\min ^{-1}\right), K_{2}\left(\mathrm{~g} \mathrm{mg}^{-1} \min ^{-1}\right)$, and $K_{i}\left(\mathrm{mg} \mathrm{g}^{-1} \mathrm{~min}^{-1 / 2}\right)$ are the pseudo-first-order, pseudo-second-order, and intraparticle diffusion rate constant, respectively.

Accordingly, the experimental data were fitted to these kinetics models. The slopes and intercepts were calculated from the equation of straight line obtained. The data obtained along with $R^{2}$ values are presented in Table 2. The sorption system will follow a specific kinetic model if $R^{2}$ value exceeds 0.98 and $q_{e}^{\text {cal }}$ value is close to that of the experimental value [37]. On the basis of $R^{2}$ values, Ho's pseudo-second-order kinetic model was proficient to explain the kinetics of the process (Figure 7). The values of $q_{e}^{\exp }$ and $q_{e}^{\text {cal }}$ were relatively closer for Ho's pseudo-second-order model rather than the Lagergren pseudo-first-order model. This is in accordance with the previous studies that Ho's pseudo-second-order kinetic model was followed in biosorption by agricultural materials [21]. From Table 2, in the case of pseudo-secondorder kinetic model it is very clear that as the initial concentration of $\mathrm{MB}$ increases, the value of $q_{e}^{\exp }$ also increases because, at high concentration, the great competition for the vacant sites leads to the higher sorption rates [41]. There are four consecutive steps used to describe the mechanism of adsorption process. These are as follow:

(1) Adsorbate ions are transported to the liquid film or boundary layer from bulk liquid, surrounding the adsorbent 


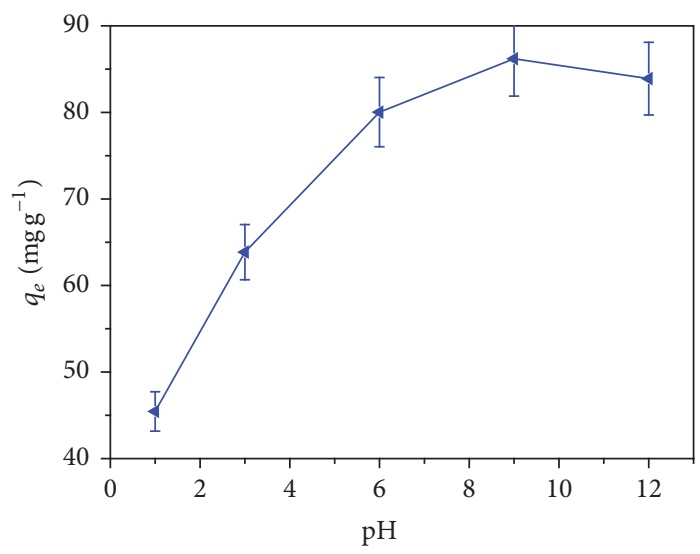

(a)

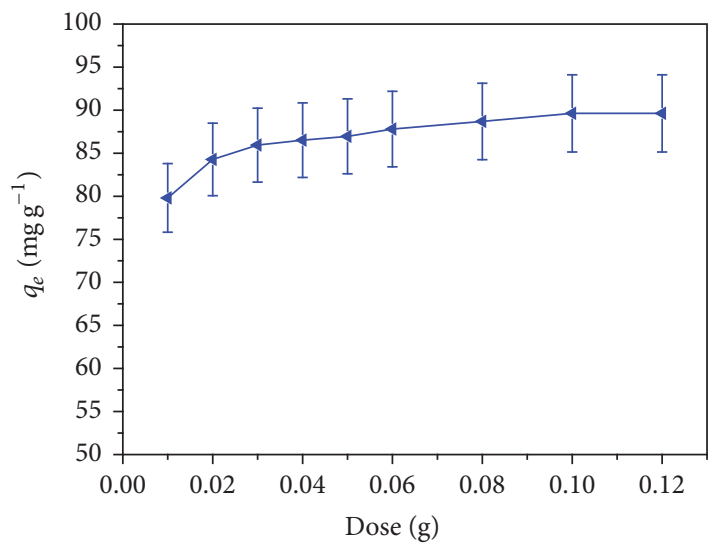

(c)

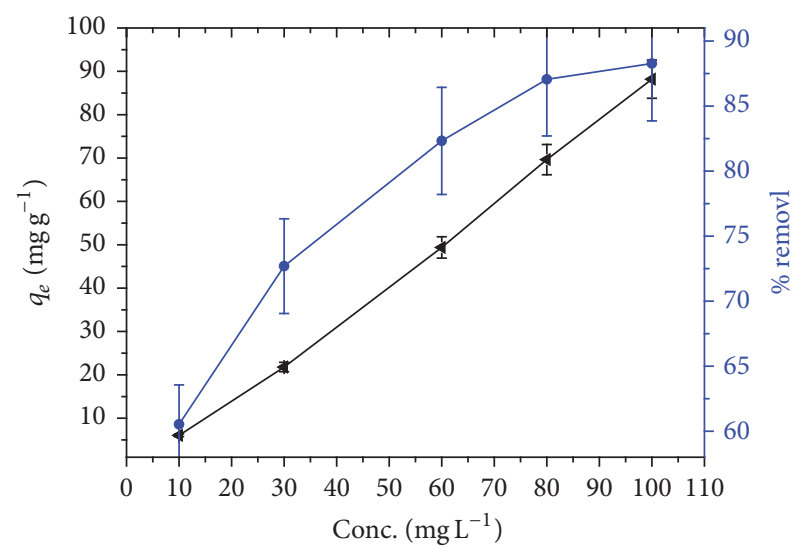

(b)

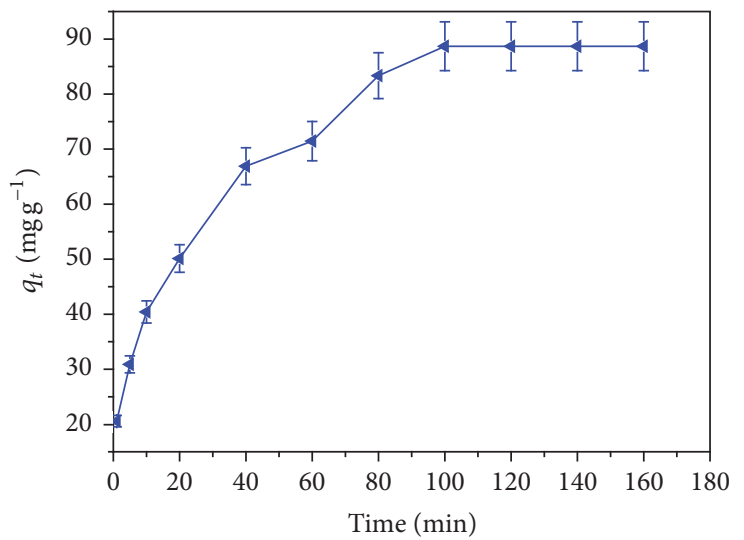

(d)

FIGURE 4: Adsorption studies for MB dye onto CLP (initial concentration: $100 \mathrm{ppm}$, mass of adsorbent $=0.02 \mathrm{~g}$, volume of adsorbate $=20 \mathrm{~mL}$, and agitation: $90 \mathrm{rpm}, \mathrm{RT})$.

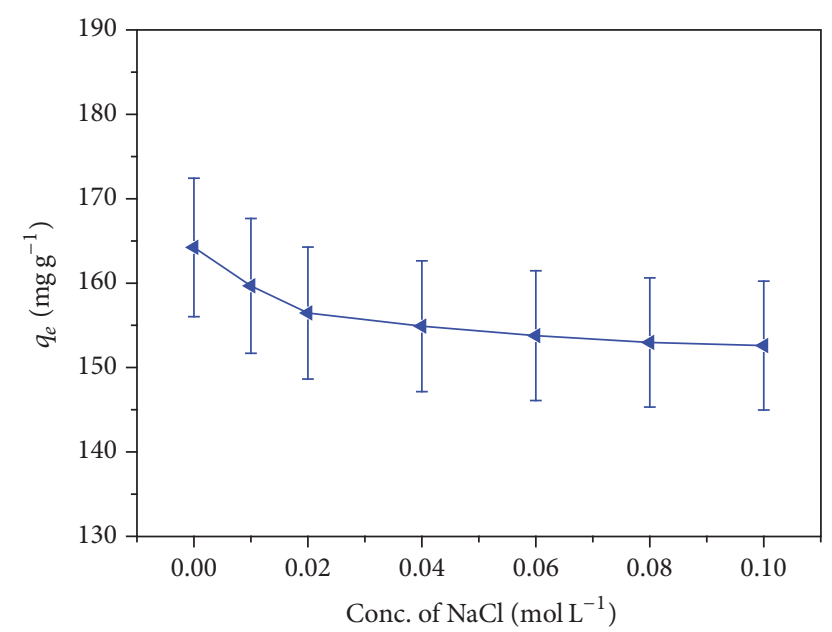

FigURE 5: Effect of ionic strength on the adsorption of methylene blue over CLP (concentration: $100 \mathrm{mg} \mathrm{L}^{-1}$, temperature: $303 \mathrm{~K}$, and dose: $0.1 \mathrm{~g})$.

(2) Adsorbate ions are transported from boundary film to external surface of the adsorbent during the surface diffusion phenomenon

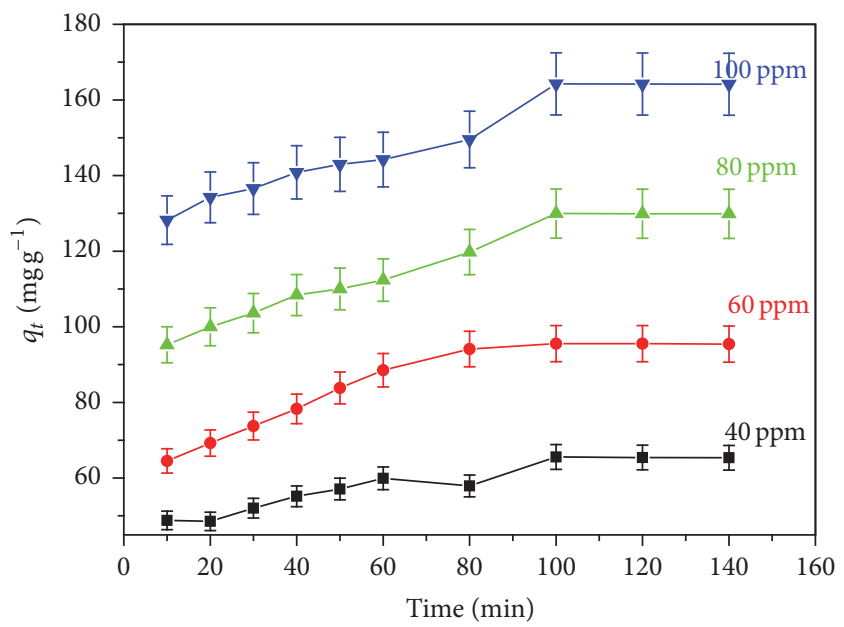

Figure 6: Effect of contact time on MB adsorption onto CLP.

(3) Adsorbate ions are transferred from the surface to the intraparticle active sites of the adsorbent during the pore-diffusion phenomenon 


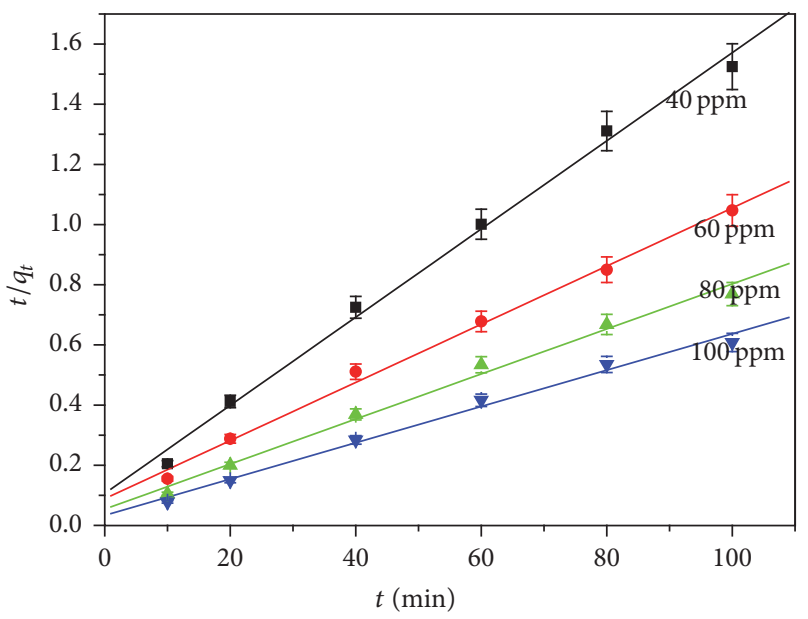

Figure 7: Pseudo-second-order kinetic plots for the adsorption of MB onto CLP (dose: $0.1 \mathrm{~g}$, temperature: $303 \mathrm{~K}$ ).

TABLE 2: Adsorption kinetic parameters for MB adsorption.

(a)

\begin{tabular}{lcccc}
\hline \multirow{2}{*}{$C_{i}\left(\mathrm{mg} \mathrm{L}^{-1}\right)$} & \multicolumn{4}{c}{ Pseudo-first-order kinetic parameters } \\
& $q_{e}^{\exp }\left(\mathrm{mg} \mathrm{g}^{-1}\right)$ & $q_{e}^{\text {cal }}\left(\mathrm{mg} \mathrm{g}^{-1}\right)$ & $K_{1}$ & $R^{2}$ \\
\hline 40 & 65.573 & 22.780 & 0.021 & 0.918 \\
60 & 95.554 & 63.351 & 0.0423 & 0.965 \\
80 & 129.958 & 42.093 & 0.0166 & 0.974 \\
100 & 164.230 & 40.021 & 0.0124 & 0.978 \\
\hline
\end{tabular}

(b)

\begin{tabular}{lcccc}
\hline \multirow{2}{*}{$C_{i}\left(\mathrm{mg} \mathrm{L}^{-1}\right)$} & \multicolumn{4}{c}{ Pseudo-second-order kinetic parameters } \\
& $q_{e}^{\exp }\left(\mathrm{mg} \mathrm{g}^{-1}\right)$ & $q_{e}^{\text {cal }}\left(\mathrm{mg} \mathrm{g}^{-1}\right)$ & $K_{2}$ & $R^{2}$ \\
\hline 40 & 65.573 & 68.027 & 0.0021 & 0.994 \\
60 & 95.554 & 103.093 & 0.0012 & 0.995 \\
80 & 129.958 & 133.333 & 0.0010 & 0.990 \\
100 & 164.230 & 166.667 & 0.0011 & 0.991 \\
\hline
\end{tabular}

(c)

\begin{tabular}{lccc}
\hline \multirow{2}{*}{$C_{i}\left(\mathrm{mg} \mathrm{L}^{-1}\right)$} & \multicolumn{3}{c}{ Intraparticle diffusion parameters } \\
& $K_{i}\left(\mathrm{mg} \mathrm{g}^{-1} \mathrm{~min}^{-1 / 2}\right)$ & $C$ & $R^{2}$ \\
\hline 40 & 2.578 & 39.03 & 0.961 \\
60 & 4.927 & 48.31 & 0.983 \\
80 & 4.765 & 78.66 & 0.965 \\
100 & 4.578 & 112.5 & 0.914 \\
\hline
\end{tabular}

TABLE 3: Adsorption isotherm parameters for adsorption of $M B$ on CLP.

\begin{tabular}{lcccc}
\hline \multicolumn{5}{c}{ Freundlich parameters } \\
$q_{e}^{\mathrm{cal}}\left(\mathrm{mg} \mathrm{g}^{-1}\right)$ & $K_{F}$ & $n$ & $R^{2}$ & $\chi^{2}$ (chi square) \\
\hline 149.22 & 10.879 & 1.101 & 0.989 & 1.509 \\
\hline
\end{tabular}

(4) There are sorption and desorption that take place within the particle and on the external surface
The first and fourth steps do not belong to the rate controlling steps because in the first step there is no involvement of adsorbent and the fourth step is a very rapid process. Therefore, surface or pore-diffusion may be the rate controlling steps [42]. Weber and Morris' model is widely used to predict the rate controlling step [40]. The calculated intraparticle diffusion model parameters for methylene blue adsorption onto the CLP are listed in Table 3. On the basis of result obtained, it may be concluded that intraparticle diffusion is not the rate controlling mechanism for the adsorption of $\mathrm{MB}$ dye from aqueous solution on the surface of CLP [41].

3.7. Adsorption Isotherms. The adsorption isotherms perform significant role in the design of any adsorption system. In this study Langmuir, Freundlich, and Temkin adsorption isotherm models were used to describe the distribution of adsorbate molecule between the solid phase and the liquid phase at the attainment of adsorption equilibrium. The experiment of the adsorption isotherms was conducted by adding $0.1 \mathrm{~g}$ of adsorbent dose into $20 \mathrm{~mL}$ of adsorbate solution at room temperature for predetermined time. The adsorption capacity of the adsorbent was calculated by using (1). Since the experimental data is obtained when applied to these isotherm models, it does not follow the Langmuir and Temkin models, so these were omitted. According to Freundlich isotherm model, adsorption takes place on heterogeneous surfaces and there is interaction between adsorbate molecules adsorbed that gives infinite surface coverage. The equation used to describe the Freundlich isotherm can be written as

$$
q_{e}=K_{F} \cdot C_{e}^{1 / n},
$$

where $q_{e}$ is the quantity of methylene blue adsorbed per $g$ of adsorbent $\left(\mathrm{mgg}^{-1}\right)$ and $C_{e}$ is the equilibrium concentration of methylene blue in the solution $\left(\mathrm{mg} \mathrm{L}^{-1}\right)$. The Freundlich constant $K_{F}$ is the maximum multilayer adsorption capacity and $n$ is the adsorption intensity [43]. The Logarithm of both sides of (7) expresses the linear form of the Freundlich isotherm, and Figure 8 is a plot $\log q_{e}$ versus $\log C_{e}$ used to obtain the values of $K_{F}$ and $1 / n$.

$$
\log q_{e}=\log K_{F}+\frac{1}{n} \log C_{e} .
$$

The heterogeneity factor $n$ can be used to indicate whether the adsorption is linear $(n=1)$, a chemical process $(n<1)$, or a physical process $(n>1)$. In the present study, Table 3 shows that value of the heterogeneity factor is greater than $1(n>1)$ indicating that the adsorption of MB dye at the surface of CLP is physical in nature. The high $K_{F}$ value gives the adsorption of aggregated molecule which is favorable at $303 \mathrm{~K}$. The calculated adsorption capacity $\left(q_{e}^{\mathrm{cal}}\right)$ was found to be $149.22 \mathrm{mg} \mathrm{g}^{-1}$ that is very close to the experimental adsorption capacity $\left(q_{e}^{\exp }\right)$ having the $R^{2}$ value near 1 and minimum chi square error $\left(\chi^{2}\right)$.

3.8. Thermodynamic Studies: Effect of Temperature. To see the effect of temperature on the adsorption of methylene blue dye on to the surface of CLP, a series of experiments were 
TABLE 4: Thermodynamic parameters for adsorption of MB on CLP.

\begin{tabular}{lcccc}
\hline Adsorption system & $\Delta H^{0}\left(\mathrm{~kJ} \mathrm{~mol}^{-1}\right)$ & $\Delta S^{0}\left(\mathrm{~kJ} \mathrm{~mol}^{-1} \mathrm{~K}^{-1}\right)$ & \multicolumn{3}{c}{$\Delta G^{0}\left(\mathrm{~kJ} \mathrm{~mol}^{-1}\right)$} & $303 \mathrm{~K}$ & $313 \mathrm{~K}$ & $323 \mathrm{~K}$ \\
\hline CLP-MB & -18.015 & -0.041 & -5.531 & -5.119
\end{tabular}

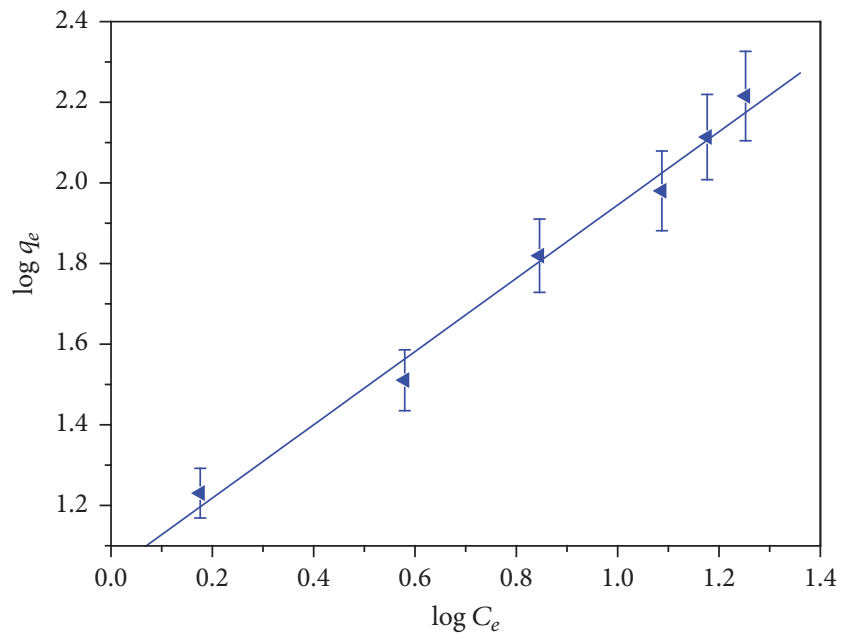

FIgURE 8: Freundlich isotherm for the adsorption of MB onto CLP.

carried out at $303 \mathrm{~K}, 313 \mathrm{~K}$, and $323 \mathrm{~K}$. It was found that the adsorption capacity decreased from $164.23 \mathrm{mgg}^{-1}$ to $149.58 \mathrm{mgg}^{-1}$ as the temperature of system was increased from $303 \mathrm{~K}$ to $323 \mathrm{~K}$. This trend may be due to the affinity of the dye molecules to outflow to the bulk phase from the solid phase with an increase in temperature of the solution [33]. The thermodynamic parameters were calculated by using the following equations:

$$
\begin{aligned}
K_{d} & =\frac{q_{e}}{C_{e}}, \\
\Delta G^{0} & =-R T \ln K_{d}, \\
\ln K_{d} & =\frac{\Delta S^{0}}{R}-\frac{\Delta H^{0}}{R T},
\end{aligned}
$$

where $K_{d}$ is distribution coefficient, $R$ is the universal gas constant $\left(\mathrm{J} \mathrm{mol}^{-1} \mathrm{~K}^{-1}\right), T$ is absolute temperature of the solution, and $\Delta G^{0}, \Delta S^{0}$, and $\Delta H^{0}$ are Gibb's free energy $\left(\mathrm{kJ} \mathrm{mol}^{-1}\right)$, Change in entropy $\left(\mathrm{kJ} \mathrm{mol}^{-1} \mathrm{~K}\right)$, and change in enthalpy $\left(\mathrm{kJ} \mathrm{mol}^{-1}\right)$, respectively [37].

The slopes $\left(-\Delta H^{0} / R\right)$ and intercepts $\left(\Delta S^{0} / R\right)$ of the Figure 9 give the values of $\Delta S^{0}$ and $\Delta H^{0}$. The $\Delta G^{0}$ values were calculated using (10). Figure 10 showed a plot of $\Delta G^{0}$ versus $T$ yielding a straight line. The values of thermodynamics parameters obtained are summarized in Table 4 . The negative value of Gibb's free energy change showed that the adsorption of MB dye at the surface of the CLP was feasible and spontaneous in nature. The negative value of $\Delta S^{0}$ and $\Delta H^{0}$ shows the decrease in the randomness at the CLP-MB interface during the adsorption and exothermic nature for the overall process,

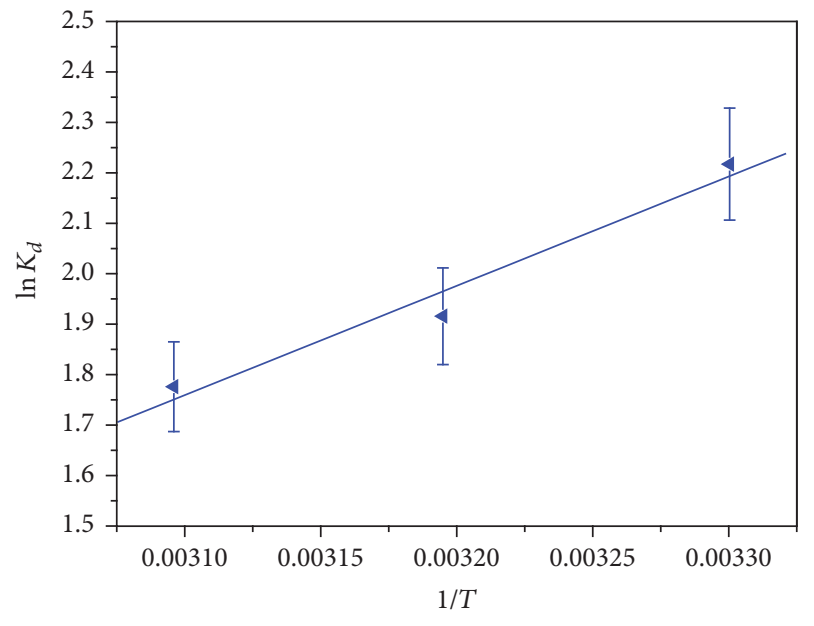

Figure 9: Plot of $\ln K_{d}$ versus $1 / T$ for the adsorption of $\mathrm{MB}$ onto CLP.

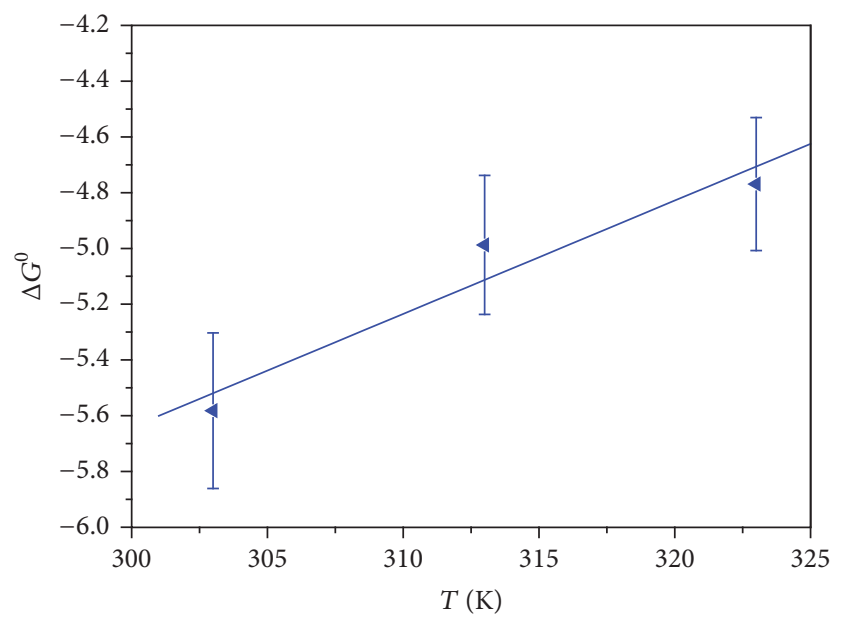

Figure 10: Plot of $\Delta G^{0}$ versus $T$ for the adsorption of MB onto CLP.

respectively. Further, $\Delta H^{0}<40 \mathrm{~kJ} / \mathrm{mol}$ shows that the nature of the sorption process was physisorption $[33,44]$.

\section{Conclusion}

The current study revealed that the cauliflower leaf powder, an agricultural waste produced after harvesting the crop, can be used as an adsorbent for the removal of methylene blue dye from synthetic aqueous solutions. The quantity of dye adsorbed was found to vary with initial solution concentration, $\mathrm{pH}$, adsorbent dose, and contact time. The quantity of dye uptake was found to increase with increase in initial concentration of dye solution and contact time and found to 
decrease with increase in adsorbent dosage but the percent removal increases. The sorption data were found to follow pseudo-second-order kinetics since amounts of methylene blue dye obtained experimentally, that is, $164.23 \mathrm{mg} \mathrm{g}^{-1}$, and calculated, that is, $166.66 \mathrm{mg} \mathrm{g}^{-1}$, from the plot are close to one another having regression value 0.991. Equilibrium data were fitted very well in Freundlich isotherm equation approving the sorption capacity of methylene blue onto cauliflower leaf powder with a sorption capacity of $149.22 \mathrm{mg} \mathrm{g}^{-1}$ having regression value 0.989 and minimum chi square error 1.5 showing the suitability of this model to describe the adsorption of MB dye onto CLP. The negative values of $\Delta G^{0}$ and $\Delta H^{0}$ indicate that the adsorption process is spontaneous, feasible, and exothermic in nature.

\section{Competing Interests}

The authors declare that there is no conflict of interests regarding the publication of this research paper.

\section{Acknowledgments}

Authors are thankful to the chairman of Department of chemistry, AMU, Aligarh, UGC, SAP (DRS-II and DST-FIST and PURSE-II) for providing research facilities.

\section{References}

[1] C. A. P. Almeida, N. A. Debacher, A. J. Downs, L. Cottet, and C. A. D. Mello, "Removal of methylene blue from colored effluents by adsorption on montmorillonite clay," Journal of Colloid and Interface Science, vol. 332, no. 1, pp. 46-53, 2009.

[2] G. Crini, "Non-conventional low-cost adsorbents for dye removal: a review," Bioresource Technology, vol. 97, no. 9, pp. 10611085, 2006.

[3] D. Inthorn, S. Singhtho, P. Thiravetyan, and E. Khan, "Decolorization of basic, direct and reactive dyes by pre-treated narrow-leaved cattail (Typha angustifolia Linn.)," Bioresource Technology, vol. 94, no. 3, pp. 299-306, 2004.

[4] K. K. H. Choy, G. McKay, and J. F. Porter, "Sorption of acid dyes from effluents using activated carbon," Resources Conservation and Recycling, vol. 27, no. 1-2, pp. 57-71, 1999.

[5] P. S. Kumar, S. Ramalingam, and K. Sathishkumar, "Removal of methylene blue dye from aqueous solution by activated carbon prepared from cashew nut shell as a new low-cost adsorbent," Korean Journal of Chemical Engineering, vol. 28, no. 1, pp. 149$155,2011$.

[6] D. Ghosh and K. G. Bhattacharyya, "Adsorption of methylene blue on kaolinite," Applied Clay Science, vol. 20, no. 6, pp. 295300, 2002.

[7] T. Robinson, G. McMullan, R. Marchant, and P. Nigam, "Remediation of dyes in textile effluent: a critical review on current treatment technologies with a proposed alternative," Bioresource Technology, vol. 77, no. 3, pp. 247-255, 2001.

[8] E. Forgacs, T. Cserháti, and G. Oros, "Removal of synthetic dyes from wastewaters: a review," Environment International, vol. 30, no. 7, pp. 953-971, 2004.

[9] S.-M. Lee and S.-T. Ong, "Oxalic acid modified rice hull as a sorbent for methylene blue removal," APCBEE Procedia, vol. 9, pp. 165-169, 2014.
[10] M. Rafatullah, O. Sulaiman, R. Hashim, and A. Ahmad, "Adsorption of methylene blue on low-cost adsorbents: a review," Journal of Hazardous Materials, vol. 177, no. 1-3, pp. 70-80, 2010.

[11] B. H. Hameed and A. A. Ahmad, "Batch adsorption of methylene blue from aqueous solution by garlic peel, an agricultural waste biomass," Journal of Hazardous Materials, vol. 164, no. 2-3, pp. 870-875, 2009.

[12] N. Gupta, A. K. Kushwaha, and M. C. Chattopadhyaya, "Application of potato (Solanum tuberosum) plant wastes for the removal of methylene blue and malachite green dye from aqueous solution," Arabian Journal of Chemistry, vol. 9, supplement 1, pp. S707-S716, 2016.

[13] A. K. Kushwaha, N. Gupta, and M. C. Chattopadhyaya, "Removal of cationic methylene blue and malachite green dyes from aqueous solution by waste materials of Daucus carota," Journal of Saudi Chemical Society, vol. 18, no. 3, pp. 200-207, 2014.

[14] M. J. Ahmed and S. K. Dhedan, "Equilibrium isotherms and kinetics modeling of methylene blue adsorption on agricultural wastes-based activated carbons," Fluid Phase Equilibria, vol. 317, pp. 9-14, 2012.

[15] M. Ertaş, B. Acemioğlu, M. Hakkı Alma, and M. Usta, "Removal of methylene blue from aqueous solution using cotton stalk, cotton waste and cotton dust," Journal of Hazardous Materials, vol. 183, no. 1-3, pp. 421-427, 2010.

[16] A. Ebrahimian and E. Saberikhah, "Alkali treated Foumanat tea waste as an efficient adsorbent for methylene blue adsorption from aqueous solution," Water Resources Industry, vol. 6, pp. 6480, 2014.

[17] G. Karacetin, S. Sivrikaya, and M. Imamoglu, "Adsorption of methylene blue from aqueous solutions by activated carbon prepared from hazelnut husk using zinc chloride," Journal of Analytical and Applied Pyrolysis, vol. 110, pp. 270-276, 2014.

[18] P. Sharma, R. Kaur, B. Chinnappan, and W. Chung, "Removal of methylene blue from aqueous waste using rice husk and rice husk ash," Desalination, vol. 259, no. 1-3, pp. 249-257, 2010.

[19] M. T. Uddin, M. A. Islam, S. Mahmud, and M. Rukanuzzaman, "Adsorptive removal of methylene blue by tea waste," Journal of Hazardous Materials, vol. 164, no. 1, pp. 53-60, 2009.

[20] F. A. Pavan, E. C. Lima, S. L. P. Dias, and A. C. Mazzocato, "Methylene blue biosorption from aqueous solutions by yellow passion fruit waste," Journal of Hazardous Materials, vol. 150, no. 3, pp. 703-712, 2008.

[21] W. Hassan, U. F. Gaur, M. A.-K. Ahmad, M. Athar, and M. Khan, "Potential biosorbent, Haloxylon recurvum plant stems, for the removal of methylene blue dye," Arabian Journal of Chemistry, 2013.

[22] J. Liu, X. Li, J. Luo, C. Duan, H. Hu, and G. Qian, "Enhanced decolourisation of methylene blue by LDH-bacteria aggregates with bioregeneration," The Chemical Engineering Journal, vol. 242, pp. 187-194, 2014.

[23] C.-H. Weng, Y.-T. Lin, and T.-W. Tzeng, "Removal of methylene blue from aqueous solution by adsorption onto pineapple leaf powder," Journal of Hazardous Materials, vol. 170, no. 1, pp. 417424, 2009.

[24] D. Mitrogiannis, G. Markou, A. Çelekli, and H. Bozkurt, "Biosorption of methylene blue onto Arthrospira platensis biomass: kinetic, equilibrium and thermodynamic studies," Journal of Environmental Chemical Engineering, vol. 3, no. 2, pp. 670-680, 2015.

[25] A. Ahmad, M. Rafatullah, O. Sulaiman, M. H. Ibrahim, and R. Hashim, "Scavenging behaviour of meranti sawdust in the 
removal of methylene blue from aqueous solution," Journal of Hazardous Materials, vol. 170, no. 1, pp. 357-365, 2009.

[26] R. Gnanasambandam and A. Proctor, "Determination of pectin degree of esterification by diffuse reflectance Fourier transform infrared spectroscopy," Food Chemistry, vol. 68, no. 3, pp. 327$332,2000$.

[27] O. Sulaiman, M. Hazim, M. Amini, R. Hashim, A. Ahmad, and M. Rafatullah, "Adsorption equilibrium and thermodynamic studies of copper (II) ions from aqueous solutions by oil palm leaves," International Journal of Chemical Reactor Engineering, vol. 8, no. 1, 2010.

[28] N. S. Maurya, A. K. Mittal, P. Cornel, and E. Rother, "Biosorption of dyes using dead macro fungi: effect of dye structure, ionic strength and pH," Bioresource Technology, vol. 97, no. 3, pp. 512-521, 2006.

[29] M. J. Iqbal and M. N. Ashiq, "Adsorption of dyes from aqueous solutions on activated charcoal," Journal of Hazardous Materials, vol. 139, no. 1, pp. 57-66, 2007.

[30] B. H. Hameed, "Equilibrium and kinetic studies of methyl violet sorption by agricultural waste," Journal of Hazardous Materials, vol. 154, no. 1-3, pp. 204-212, 2008.

[31] V. Ponnusami, V. Gunasekar, and S. N. Srivastava, "Kinetics of methylene blue removal from aqueous solution using gulmohar (Delonix regia) plant leaf powder: multivariate regression analysis," Journal of Hazardous Materials, vol. 169, no. 1-3, pp. 119-127, 2009.

[32] V. Vadivelan and K. V. Kumar, "Equilibrium, kinetics, mechanism, and process design for the sorption of methylene blue onto rice husk," Journal of Colloid and Interface Science, vol. 286, no. 1, pp. 90-100, 2005.

[33] N. Gupta, A. K. Kushwaha, and M. C. Chattopadhyaya, "Adsorption studies of cationic dyes onto Ashoka (Saraca asoca) leaf powder," Journal of the Taiwan Institute of Chemical Engineers, vol. 43, no. 4, pp. 604-613, 2012.

[34] C. F. Iscen, I. Kiran, and S. Ilhan, "Biosorption of reactive black 5 dye by Penicillium restrictum: the kinetic study," Journal of Hazardous Materials, vol. 143, no. 1-2, pp. 335-340, 2007.

[35] A. A. Abia and E. D. Asuquo, "Kinetics of $\mathrm{Cd}^{2+}$ and $\mathrm{Cr}^{3+}$ sorption from aqueous solutions using mercaptoacetic acid modified and unmodified oil palm fruit fibre(Elaeis guineensis) adsorbents," Tsinghua Science and Technology, vol. 12, no. 4, pp. 485-492, 2007.

[36] V. Jaikumar and V. Ramamurthi, "Effect of biosorption parameters kinetics isotherm and thermodynamics for acid green dye biosorption from aqueous solution by brewery waste," International Journal of Chemistry, vol. 1, no. 1, pp. 2-12, 2007.

[37] U. Farooq, J. A. Kozinski, M. A. Khan, and M. Athar, "Biosorption of heavy metal ions using wheat based biosorbents-a review of the recent literature," Bioresource Technology, vol. 101, no. 14, pp. 5043-5053, 2010.

[38] M. T. Uddin, M. Rukanuzzaman, M. M. R. Khan, and M. A. Islam, "Jackfruit (Artocarpus heterophyllus) leaf powder: aneffective adsorbent for removal of methylene blue from aqueous solutions," Indian Journal of Chemical Technology, vol. 16, no. 2, pp. 142-149, 2009.

[39] Y. S. Ho and G. McKay, "Pseudo-second order model for sorption processes," Process Biochemistry, vol. 34, no. 5, pp. 451-465, 1999.

[40] W. J. Weber and J. C. Morris, "Kinetics of adsorption on carbon from solution," Journal of the Sanitary Engineering Division, vol. 89, no. 2, pp. 31-60, 1963.
[41] S. K. Theydan and M. J. Ahmed, "Adsorption of methylene blue onto biomass-based activated carbon by $\mathrm{FeCl}_{3}$ activation: equilibrium, kinetics, and thermodynamic studies," Journal of Analytical and Applied Pyrolysis, vol. 97, pp. 116-122, 2012.

[42] Y. Li, Q. Du, X. Wang et al., "Removal of lead from aqueous solution by activated carbon prepared from Enteromorpha prolifera by zinc chloride activation," Journal of Hazardous Materials, vol. 183, no. 1-3, pp. 583-589, 2010.

[43] H. Hussein, S. F. Ibrahim, K. Kandeel, and H. Moawad, "Biosorption of heavy metals from waste water using Pseudomonas sp." Electronic Journal of Biotechnology, vol. 7, no. 1, pp. 45-53, 2004.

[44] Y. X. Chen and G. Y. Wang, "Adsorption properties of oxidized carboxymethyl starch and cross-linked carboxymethyl starch for calcium ion," Colloids and Surfaces A, vol. 289, no. 1-3, pp. 75-83, 2006. 

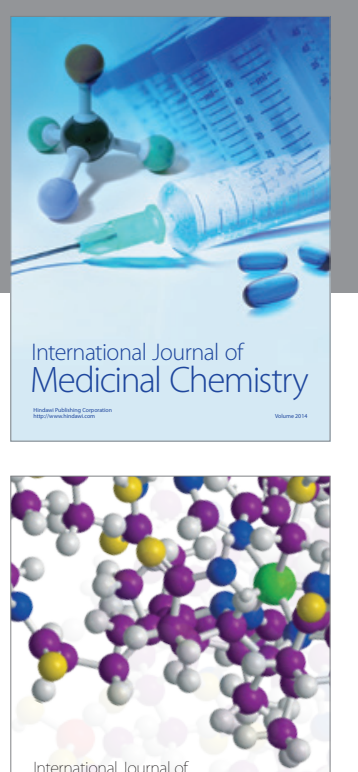

Carbohydrate Chemistry

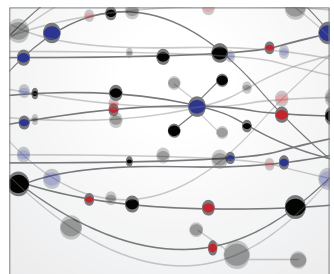

The Scientific World Journal
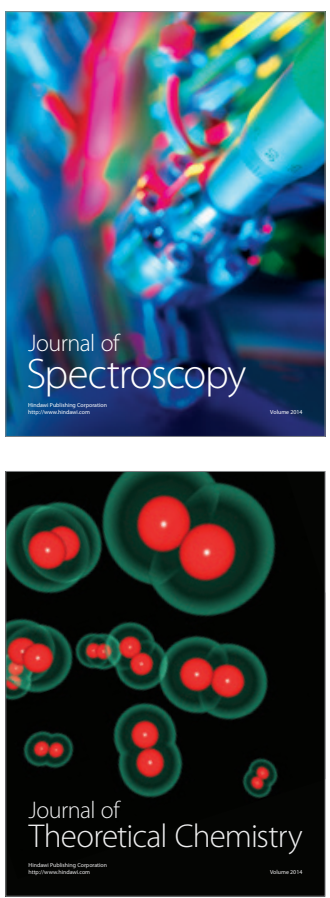
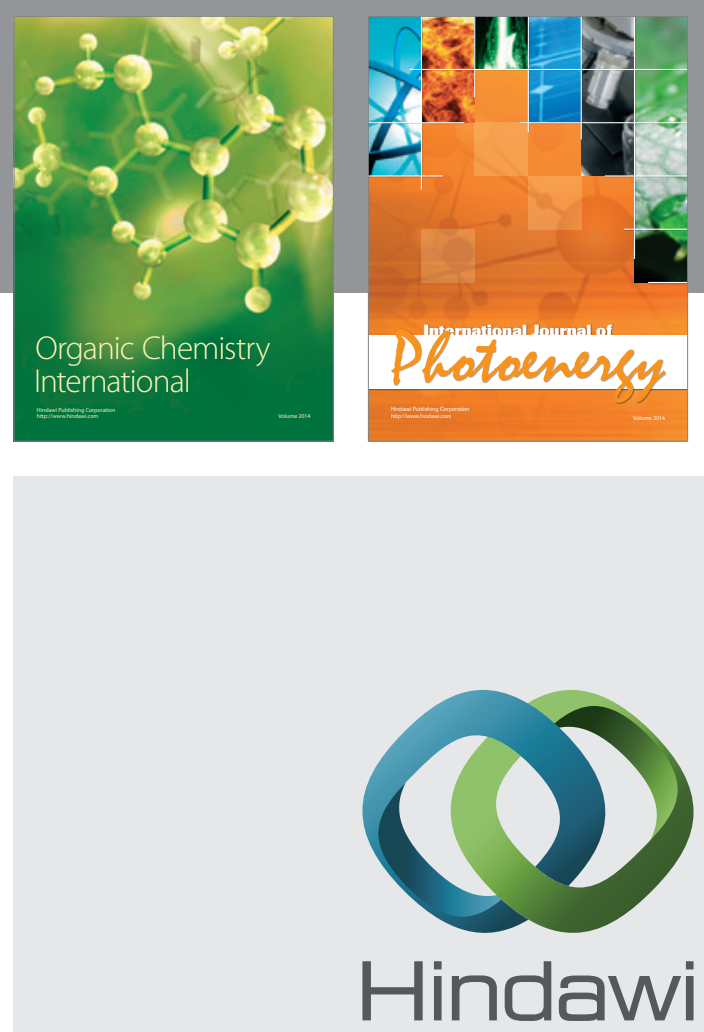

Submit your manuscripts at

http://www.hindawi.com

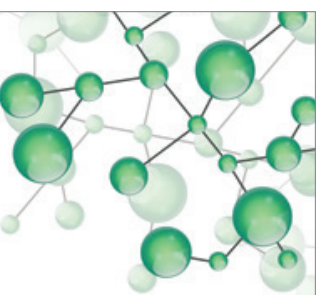

International Journal of

Inorganic Chemistry

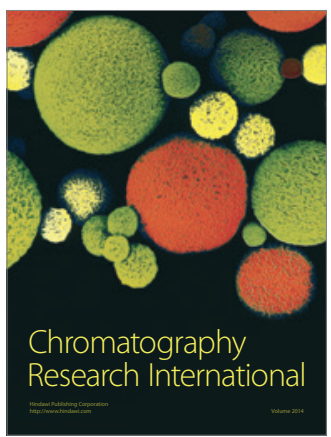

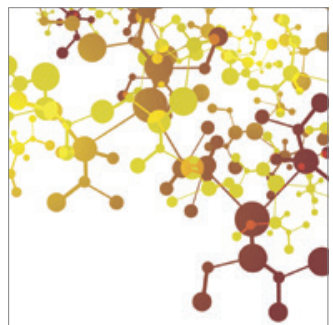

Applied Chemistry
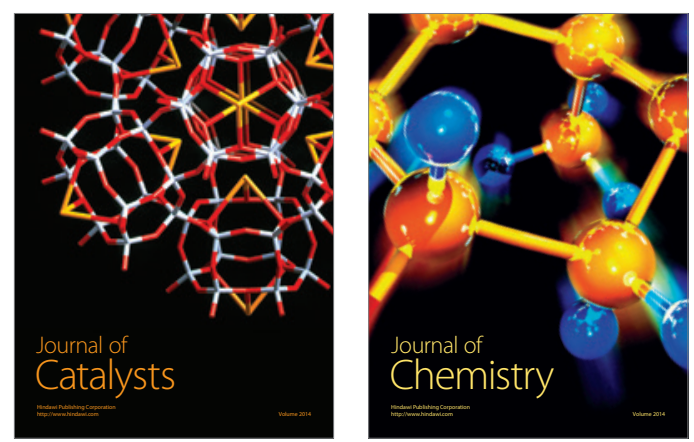
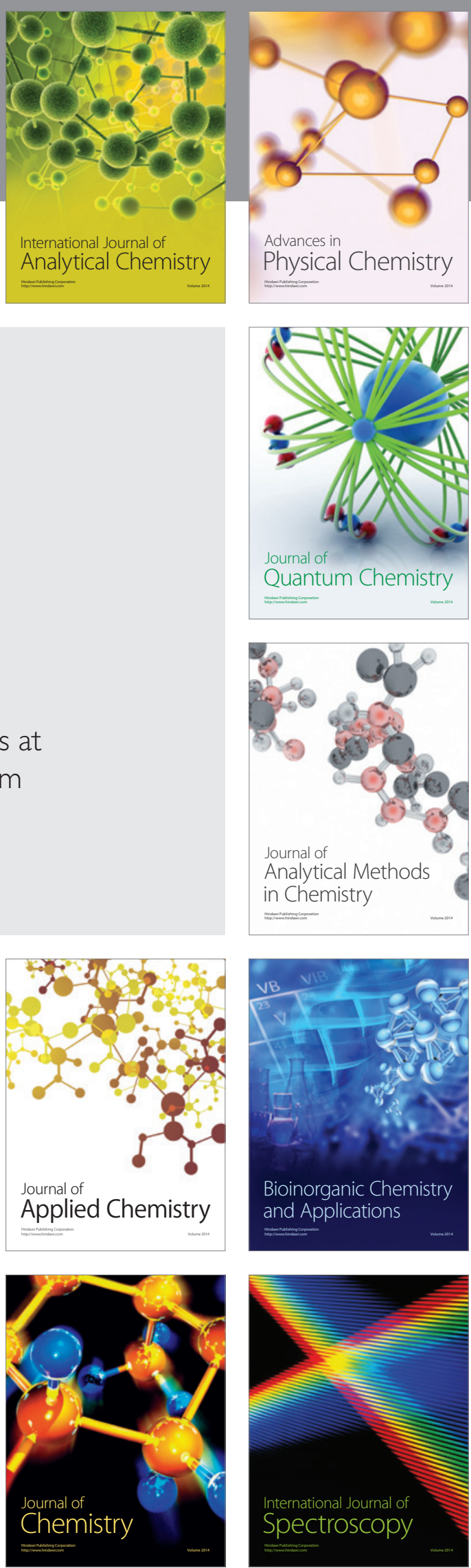